\title{
Effect of 17a-methyltestosterone (MT) on oxidation stress in the liver of juvenile GIFT tilapia, Oreochromis niloticus
}

\author{
Yao Zheng ${ }^{1,2,3^{*}}$, Jianhong Qu ${ }^{1,2}$, Liping Qiu ${ }^{1,2}$, Limin Fan ${ }^{1,2}$, Shunlong Meng ${ }^{1,2}$, Chao Song ${ }^{1,2}$, Xuwen Bing ${ }^{1,2,3}$ \\ and Jiazhang Chen ${ }^{1,2,3^{*}}$
}

\begin{abstract}
The normal dose of 17a-methyltestosterone (MT) used in fish farming was $60 \mathrm{mg} / \mathrm{L}$, and now the analysis of residual androgens was carried out in waste water obtained from the Beijing area, which could be detected in levels ranging from 4.1 to $7.0 \mathrm{ng} / \mathrm{L}$. For the purpose of aquatic early warning, the present study clearly demonstrated that chronic exposure by higher concentration of MT than environmental relevant concentrations could trigger oxidative stress response to juvenile tilapia by modulating hepatic antioxidant enzyme activities and gene transcription. Some antioxidative parameters (T-GSH, GSH/GSSG and MDA) were significant decreased under $0.5 \mathrm{mg} / \mathrm{L}$ MT exposure at 7 and 14 days. Some antioxidant enzymes (SOD, CAT and GST) and transcriptional changes (sod and cat) were revealed significant decreases for MT treated groups at 7 days. Total antioxidant capacity was significant increased only in $5 \mathrm{mg} / \mathrm{L}$ MT exposure groups, but GR activities were not affected all through the whole exposure period. Almost all of the antioxidant enzymatic genes detected in the present study were showed significant increments for MT exposure both at 14 and 21 days, and the genotoxicity profile of antioxidant enzymatic genes were revealed dose-dependent manner. This study presented evidence that MT could result in oxidative stress response in the early stages of GIFT tilapia.
\end{abstract}

Keywords: 17a-Methyltestosterone, Antioxidant enzyme, Genotoxicity, Oreochromis niloticus, Oxidative stress

\section{Background}

$17 \alpha$-Methyltestosterone (MT), an artificial androgenic compound, is often used to induce masculinization of both secondary sex characteristics and gonads in aquatic filed studies (Homklin et al. 2009; Golan and LevaviSivan 2014; Shen et al. 2015). For example, male tilapia and Yellow catfish has grown faster than females, and MT-immersion for sexually immature hatched larvae has been used to produce mono-male groups. MT also induced organic impairment (Seki et al. 2004) associated with detoxification and antioxidant defense systems in the form of whole cytochrome P450 (CYP) biotransformation (Kim et al. 2014). Some artificial compounds targeted oxidative defense system via hormone biosynthesis

\footnotetext{
*Correspondence: zhengy@ffrc.cn; chenjz@ffrc.cn

${ }^{1}$ Freshwater Fisheries Research Center, Chinese Academy of Fishery

Sciences, No. 9 Shanshui East Rd., Wuxi 214081, Jiangsu, China

Full list of author information is available at the end of the article
}

and catalytic mechanism of CYP (Mimeault et al. 2006; Ibrahim and Harabawy 2014), and androgenic compounds directly induced antioxidant enzymatic activities and genotoxicity (Larsson et al. 2002).

Oxidative stress is an important manifestation in fish, and the oxidative damage induced by chemicals in aquatic ecosystems can be assessed through the measurements of antioxidant enzyme activities. Androgenic analogues used as oxidative stress inducers to produce excess reactive oxygen species (ROS), which resulted in hepatotoxicity. The main ROS are generated in the mitochondria (Zorov et al. 2006) and ROS detoxification could be provoked both directly by antioxidant enzymes, such as the radical-scavenging enzymes: superoxide dismutase (SOD; EC 1.15.1.1), catalase (CAT; EC 1.11.1.6), glutathione peroxidase (GPx; EC 1.11.1.9), and indirectly by stabilizing the levels of glutathione (GSH) collaboration with the assistance of glutathione-S-transferase (GST; EC 2.5.1.18) and glutathione reductase (GR; EC 1.8.1.7). 
ROS-induced oxidative stress has been considered to contribute to abnormal development during embryogenesis, more and more evidence showed oxidative stress could be an important pathogenic mechanism of neurological and developmental deficits in both animal and human.

Taken effects on fish antioxidant defense system following common freshwater pesticides (atrazine) exposure for example, usually the detected endpoint contains antioxidant enzymatic activities and genotoxicity, which had been performed in zebrafish Danio rerio (Jin et al. 2010), common carp Cyprinus carpio (Chen et al. 2015), and so on. Liver was one of the main target organ (Salaberria et al. 2009; Jin et al. 2012; Kroon et al. 2014), but hepatic transcripts was not always affected by androgenic compounds when faced to oxidative stress (Albertsson et al. 2010). Nile tilapia, Oreochromis niloticus is sensitive to the oxidative stress of pollutants and can be treated as a kind of ideal material for toxicity experiment (Meng et al. 2014a, b). Our previous study showed that hepatic SOD, CAT and GPx activities and their transcripts were increased in Nile tilapia under methomyl exposure (Meng et al. 2014a, b). GIFT strain of Nile tilapia ("GIFT tilapia" for short), a tropical species, are suitable for culture in warm waters, and very sensitive to aquatic environmental factors (Ma et al. 2015; Gabriel et al. 2015). The normal dose (MT) used in fish farming was $60 \mathrm{mg} / \mathrm{L}$ (RiveroWendt et al. 2013), and now the residual MT could be detected in waste water obtained from the Beijing area of China (4.1-7.0 ng/L; Sun et al. 2010). A decrease in egg laying rate of female Japanese quails (Coturnix cotumix japonica) and the fertility of male Japanese quails when exposed to $50-110 \mathrm{mg} / \mathrm{L}$ of MT for 3 weeks (Homklin et al. 2012). The minor deficit of the former studies only used antioxidative enzymatic activities to perform the study (Meng et al. 2014a, b; Ma et al. 2015; Gabriel et al. 2015), and fish genotoxicity may be more sensitive to pollution (Chakravarthy et al. 2014). We know MT has the potential to induce oxidative stress, the main purpose of the present study was to investigate the hepatic genotoxicity (transcriptional) and antioxidant enzymatic signature (post transcriptional) of freshwater GIFT tilapia $O$. niloticus juveniles responding to $0.5,5 \mathrm{mg} / \mathrm{L}$ MT exposure. The present study will also detect other antioxidant parameters to further testify that hepatic antioxidant defense system was impaired following MT exposure.

\section{Methods}

\section{Experimental design}

Fertilized eggs of GIFT tilapia, O. niloticus were obtained from Freshwater Fisheries Research Center of the Chinese Academy of Fishery Sciences, Yixing. One-month old O. niloticus juveniles were used in the experiment and which were acclimatized in the aquarium facility with dechlorinated tap water at $25 \pm 1{ }^{\circ} \mathrm{C}$, with $14 \mathrm{~h}: 10 \mathrm{~h}$ light/dark cycle. The experimental fish were offered feed once a day, and the feed purchased from Jiangsu Zhe Ya Food. Co. Ltd, China. Fish (from 4.04 to $4.97 \mathrm{~g}$ ) were randomly selected for exposure experiments. Throughout the experimental period, water samples were taken before and after each water change, and the experimental conditions were as follows: $\mathrm{pH}, 7.1 \pm 0.5 \mathrm{U}$; dissolved oxygen (tested by YSI 556MPS, USA), $7.16 \pm 0.16 \mathrm{mg} / \mathrm{L}$; total phosphate, $2.16 \pm 0.17 \mathrm{mg} / \mathrm{L}$; total nitrogen and ammonia nitrogen (by Nessler's reagent spectrophotometry), $0.52 \pm 0.15$ and $0.44 \pm 0.06 \mathrm{mg} / \mathrm{L}$ respectively; total water hardness (ICP-OES, Optima 7000, PerkinElmer, USA), $194.3 \pm 13.0 \mathrm{mg} / \mathrm{L} \mathrm{CaCO}_{3}$.

The GIFT tilapia juveniles $(n=360)$ were assigned to nine groups ( $n=40$ per aquarium). MT was purchased from Sigma-Aldrich (St Louis, MO, USA). One out of three group fish were exposed to $0.5 \mathrm{mg} / \mathrm{L} \mathrm{MT}$ and $5 \mathrm{mg} / \mathrm{L}$ MT respectively, and the last were reared in water without MT treatment in triplicate. Fish were exposed to test solutions for 21 days and all of the exposure solutions were replaced every $48 \mathrm{~h}$ with the fresh exposure solutions of the same concentration during the exposure experiment. The control group was also kept for 21 days with changing fresh water without MT every $48 \mathrm{~h}$. There were no statistically significant differences in bodyweight or length in the exposure experiment. During the experiment, no fish mortality was observed. From the initial exposure day, sampled the water once 2 days both in the control groups and the experimental groups in triplicate.

\section{Fish sampling}

All fish liver samples of the exposure and control groups were collected once a week. In each group per sampling point, fish liver were sampled for gene expression $(n=6)$ and biochemical analysis $(n=6)$ respectively. Particularly samples for gene expression studies were homogenized using Trizol reagent (Invitrogen, USA), frozen in liquid nitrogen and stored at $-80{ }^{\circ} \mathrm{C}$ immediately until utilization.

\section{Determination of oxidative stress}

For biochemical analyses, liver from 6 individuals per group at every sampling point was washed with ice-cold physiological salt water $(0.86 \% \mathrm{NaCl})$ thoroughly, then dried the surface with absorbent paper, weighed and killed unconsciously by a sharp blow on the head. Whole liver samples were homogenized on ice with cold $0.86 \%$ physiological salt water $(1: 9, \mathrm{w} / \mathrm{v})$, and then centrifuged at $2,500 \mathrm{r} / \mathrm{min}$ at $4{ }^{\circ} \mathrm{C}$ for $10 \mathrm{~min}$. The supernatant was analyzed for the activity assays of CAT, GPx, GR, GST, SOD and the content of MDA, GSH, the total protein 
and the total antioxidant capacity using the commercial kits purchased from Nanjing Jiancheng Bioengineering Institute in triplicate (Nanjing, China). The experiment were quantified spectrophotometrically with a PowerWave XS2 (BioTek instruments Inc, Vermont, USA).

The total protein content (recorded at $595 \mathrm{~nm}$ ) was determined using Coomassie Brilliant Blue G-250 staining (Bradford 1976). MDA content was measured by assaying the decomposition product of polyunsaturated fatty acid hydroperoxides was determined by the TBA reaction as described by Luo et al. (2006). According to the directions, the mixture was heated at constant temperature at $95^{\circ} \mathrm{C}$ for $40 \mathrm{~min}$, cooled by running water and centrifuged at $3500 \mathrm{r} / \mathrm{min}$ for $10 \mathrm{~min}$. The absorbance of the supernatant was recorded at $532 \mathrm{~nm}$. GSH (the total glutathione) content was quantified using the method of reacting with 5,5-dithiobis-2-nitrobenzoic acid (DTNB) (Beutler and Kelly 1963) and the generated yellow compound's absorbance was recorded at $420 \mathrm{~nm}$.

SOD activity was measured through the method of WST-1 by inhibiting of nitroblue tetrazolium reduction at $450 \mathrm{~nm}$ (Huang et al. 2007). The final concentration consisted of $50 \mathrm{mM}$ sodium phosphate buffer, $0.1 \mathrm{mM}$ EDTA, $0.01 \mathrm{mM}$ cytochrome c, $0.05 \mathrm{mM}$ xanthine, and $0.005 \mathrm{mM}$ xanthine oxidase. The reaction was initiated when xanthine oxidase was added to the enzyme extract at $25^{\circ} \mathrm{C}$. One unit of SOD activity is defined as the amount of enzyme required to inhibit the oxidation reaction by $50 \%$ and is expressed as $\mathrm{U} / \mathrm{mg}$ protein. CAT activity was determined by measuring hydrogen peroxide based on the production of its stable complex with ammonium molybdate at $405 \mathrm{~nm}$ (Góth 1991). The reaction system consisted of $50 \mathrm{mM}$ sodium phosphate buffer ( $\mathrm{pH} 7.0$ ) and $19 \mathrm{mM}$ hydrogen peroxide. The reaction was quantified at $25{ }^{\circ} \mathrm{C}$ by measuring the disappearance of $\mathrm{H}_{2} \mathrm{O}_{2}$. GPx activity was assayed with the spectrophotometer by surveying the decrement of the glutathione's enzymatic reaction at $412 \mathrm{~nm}$. One unit (U) of CAT and GPx activity is defined as the amount of enzyme consuming $1 \mu \mathrm{mol}$ of substrate or generating $1 \mu \mathrm{mol}$ of product per minute and refereed per milligram soluble protein (U/mg protein). GR activity was determined by monitoring the glutathione-dependent oxidation of NADPH at $340 \mathrm{~nm}$ (Schaedle 1977). GST activity was measured using 1-chloro-2,4-dinitrobenzene (CDNB) as a substrate (Zhang et al. 2004), and the enzyme activity was determined by monitoring changes in absorbance at $412 \mathrm{~nm}$. The assay contains $100 \mathrm{mM}$ sodium phosphate buffer ( $\mathrm{pH} 6.5$ ), $60 \mathrm{mM}$ glutathione (GSH), and $60 \mathrm{mM} \mathrm{CDNB}$ (dissolved in ethanol). One unit of GST activity was calculated as the amount of enzyme catalysing the conjugation of $1 \mu \mathrm{mol}$ of CDNB with GSH per minute at $25^{\circ} \mathrm{C}$.

\section{RNA extraction, reverse transcription (RT) and qRT-PCR}

Total RNAs were extracted from all fish liver of GIFT tilapia juveniles from MT exposure and the control groups with Trizol reagent (Invitrogen, USA) and further treated with RNase-free DNase I (Fermentas, Canada). To check for genomic DNA contamination and to verify the total RNA quality, we loaded the total RNA in a $1 \%$ agarose gel with $\mathrm{EtBr}$ (Sigma-Aldrich, USA) staining and checked the $18 / 28 \mathrm{~S}$ ribosomal RNAs integrity together with the normal check using the spectrophotometric method (NanoDrop 1000, Thermo Scientific, USA). After RNA quality was determined, the cDNAs were synthesized from $3 \mu \mathrm{g}$ DNase I-treated total RNA using the M-MLV First Strand cDNA Kit (Invitrogen, USA) with the oligo $(\mathrm{dT})_{12-18}$ primers in a $20 \mu \mathrm{L}$ final volume according to the instruction manual. The cDNAs were used for cloning genes and carried out analysis of gene expressions after normalization.

The qRT-PCR was performed by CFX96 Real-Time PCR System (Bio-Rad, USA) with SYBR (TaKaRa, Japan). After the normalization of each cDNA samples, the qRTPCR reactions were carried out with $1 \times$ SYBR Premix $\mathrm{Ex} \mathrm{Taq}^{\mathrm{TM}}, 0.4 \mu \mathrm{M}$ of each primer, and $2.5 \mu \mathrm{L}$ RT reaction solution in a final volume of $25 \mu \mathrm{L}$ in triplicate. The reaction was initially denatured at $95^{\circ} \mathrm{C}$ for $30 \mathrm{~s}$, followed by 40 cycles of denaturation at $95^{\circ} \mathrm{C}$ for $5 \mathrm{~s}$ and annealing at $60{ }^{\circ} \mathrm{C}$ for $30 \mathrm{~s}$. A melt curve analysis was performed at the end of each PCR thermal profile to assess the specificity of amplification.

$\beta$-Actin was the most stable reference gene under exposure of MT in our study with the selecting method described in Zheng et al. (2014) (the detail was not revealed). The qRT-PCR primers for $\beta$-actin, sod, cat, gpxl, $g r$ and gst are mentioned in Additional file 1: Table S1. Each transcript was analyzed on six individuals per each sampling point per each group. The changes of expression levels of these antioxidant genes after MT exposure were calculated by the $2^{-\Delta \Delta \mathrm{Ct}}$ method with the formula, $\mathrm{F}=2^{-\Delta \Delta \mathrm{Ct}}, \Delta \Delta \mathrm{Ct}=\left(\mathrm{C}_{\mathrm{t}}\right.$, target gene $-\mathrm{C}_{\mathrm{t}}$, $\beta$-actin $)_{\mathrm{MT}}-\left(\mathrm{C}_{\mathrm{t} \text {, target gene }}-\mathrm{C}_{\mathrm{t}, \beta \text {-actin }}\right)_{\text {control }}$ (Livak and Schmittgen 2001).

\section{Statistical analysis}

All the experimental data are shown as the mean \pm standard deviation of the mean (SD). Data were tested for normality of distribution (Shapiro-Wilk test) and homogeneity of variance (Levene's test) prior to analysis. The data were dealt with one-way ANOVA analysis followed by the LSD test (Ahmad et al. 2006) with SPSS Statistics 18.0 (SPSS Inc., Chicago, IL USA), with $P<0.05$ indicating an significant difference. Data that did not conform to assumptions of normality and homoscedasticity were transformed (lg) and then analyzed as narrated above. 


\section{Results}

\section{Antioxidant parameters following MT exposure}

The antioxidant parameters (T-GSH, GSH/GSSG, T-AOC and MDA) were showed in Fig. 1. T-GSH, GSH/ GSSG and MDA were significant decreased in $0.5 \mathrm{mg} / \mathrm{L}$ MT exposure groups at 7 and 14 days. T-GSH and MDA were significant decreased and increased for 0.5 and $5 \mathrm{mg} / \mathrm{L}$ MT exposure groups respectively at 21 days (Fig. 1A, D), while GSH/GSSG only showed significant increment in $5 \mathrm{mg} / \mathrm{L} \mathrm{MT}$ exposure groups (Fig. 1B). $\mathrm{T}$-AOC revealed significant increments in $5 \mathrm{mg} / \mathrm{L} \mathrm{MT}$ exposure groups all through the exposure time (Fig. 1C).

\section{Antioxidant enzymes}

The activities of the antioxidant enzymes (SOD, CAT, GPx, GR and GST) were revealed in Fig. 2. SOD, CAT and GST activities showed significant decreases for MT exposure at 7 days, while GPx activities showed significant increments (by 115 and $131 \%$ for 0.5 and $5 \mathrm{mg} / \mathrm{L}$ MT exposure groups respectively, Fig. 2C). GPx activities showed significant increments for MT exposure both at 14 days $(0.5 \mathrm{mg} / \mathrm{L})$ and 21 days $(0.5$ and $5 \mathrm{mg} / \mathrm{L})$, while SOD activities was significant decreased for $5 \mathrm{mg} / \mathrm{L} \mathrm{MT}$ exposure groups (Fig. 2A). CAT activities demonstrated significant decreases for MT exposure both at 14 days $(0.5 \mathrm{mg} / \mathrm{L})$ and 21 days $(0.5$ and $5 \mathrm{mg} / \mathrm{L})$. CAT activities (increased by $131 \%$ ) only showed significant increments for $5 \mathrm{mg} / \mathrm{L} \mathrm{MT}$ exposure at 14 days (Fig. 2B), while GST activities only showed significant increments for $0.5 \mathrm{mg} / \mathrm{L} \mathrm{MT}$ exposure at 14 and 21 days (Fig. 2E). GR activities were not affected all through the whole exposure period (Fig. 2D).

\section{Genotoxicology}

The gene expression profiles of the antioxidant enzymes (sod, cat, gr, gpx1 and gst) were revealed in Fig. 3. sod and cat showed significant decreases for MT exposure at 7 days (Fig. 3A, B), while gst showed significant increments (Fig. 3E). Except for sod and gpx1 transcripts at 14 days (Fig. 3A, C), all of the antioxidant enzymatic genes detected in the present study showed significant increments for MT exposure both at 14 and 21 days, and the genotoxicity profile of antioxidant enzymatic genes revealed dose-dependent manner. $g r$ and $g p x 1$ transcripts were not affected at 7 days (Fig. 3C, D).
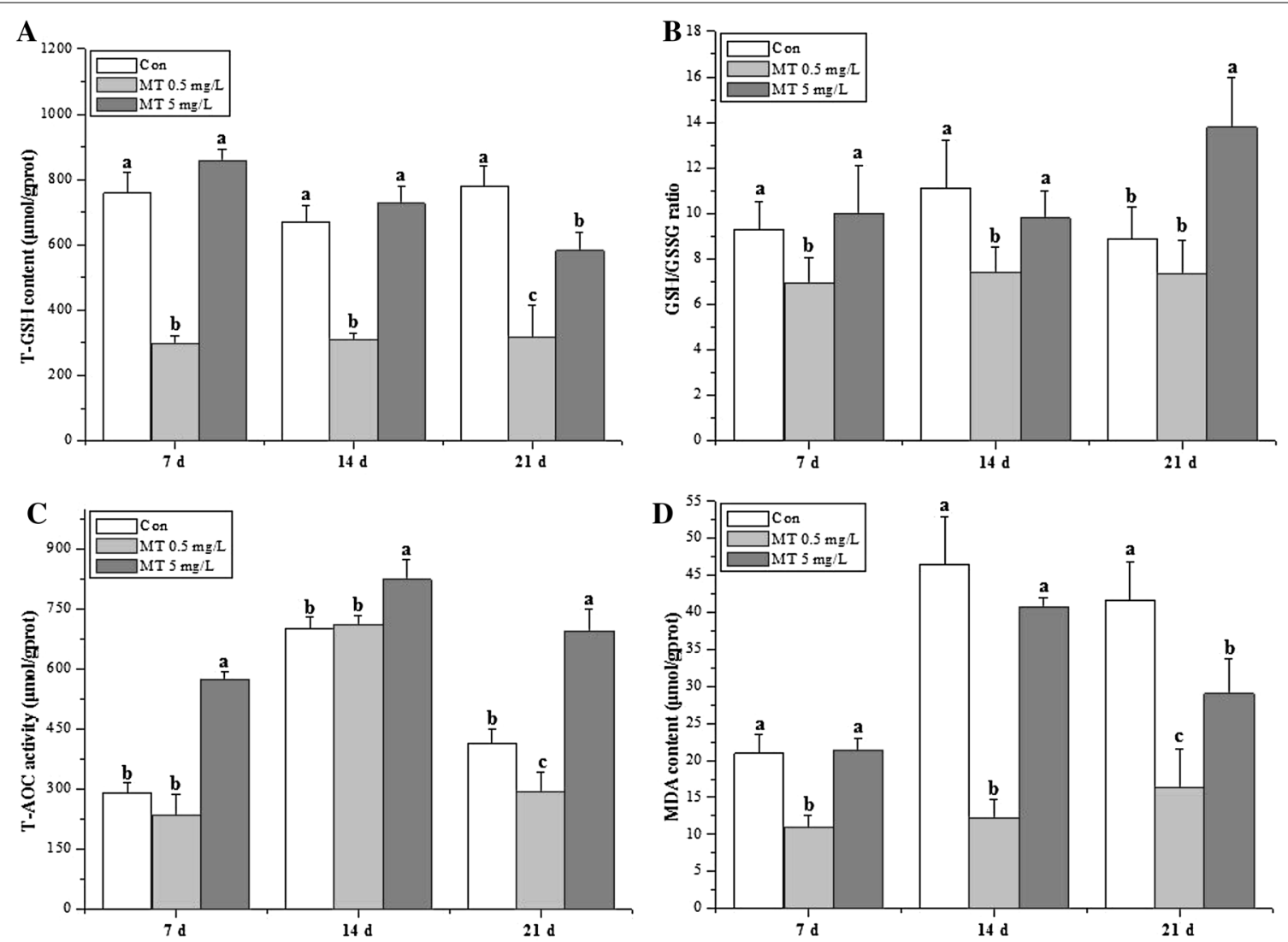

Fig. 1 Antioxidative index of O. niloticus juveniles under MT exposure. A T-GSH, B GSH/GSSG, C T-AOC, D MDA. The different lower letters indicate statistically highly significant differences $(P<0.05)$ 

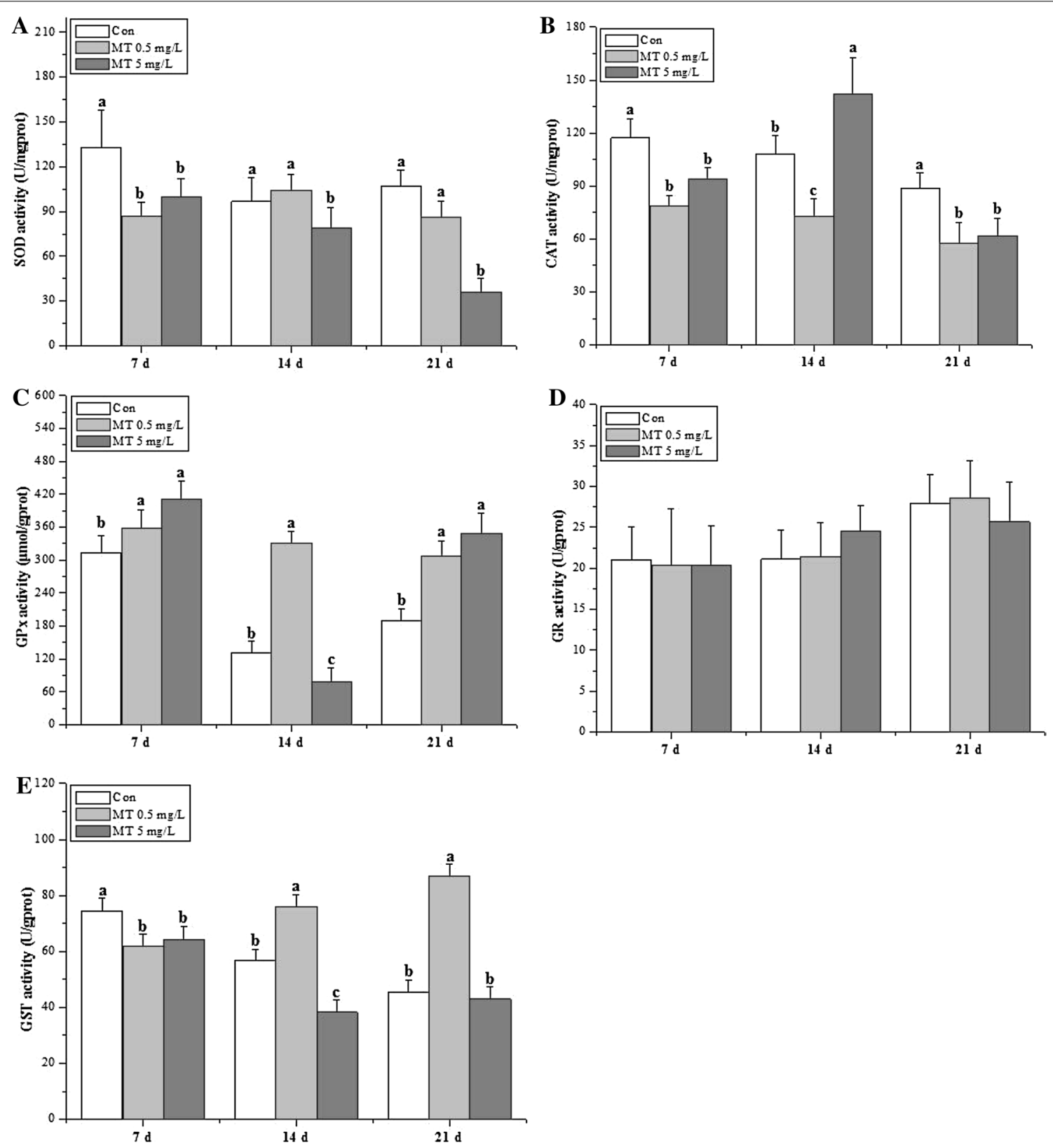

Fig. 2 Antioxidative enzymatic activities of O. niloticus juveniles under MT exposure. A SOD, B CAT, C GPX, D GR, E GST

\section{Discussion}

SOD and CAT comprise the first-line defense against oxygen toxicity and serve as early indicators of exposure to pollutants that trigger oxidative stress. GSH prevents free radical damage and helps detoxification by conjugating with chemicals, and GST is an important phase II detoxification enzyme in the form of conjugation with glutathione to produce less toxic and more water soluble compounds. Androgenic compounds directly induced antioxidant enzymatic activities and transcriptional genotoxicity
(Larsson et al. 2002). Previous studies have used Nile tilapia as chemical test model to further testify the mode of action in the metabolic mechanism of xenobiotic pollutants (Meng et al. 2014a, b). The present study presented hepatic sensitive biomarkers of juvenile GIFT tilapia following MT exposure in the form of antioxidant enzyme activities and transcripts. The antioxidative index (Fig. 1) in $5 \mathrm{mg} / \mathrm{L}$ MT exposure groups was significant higher than those in $0.5 \mathrm{mg} / \mathrm{L}$ MT exposure groups, while some antioxidative enzymatic activities (SOD, GPx, GST) in $5 \mathrm{mg} / \mathrm{L}$ 

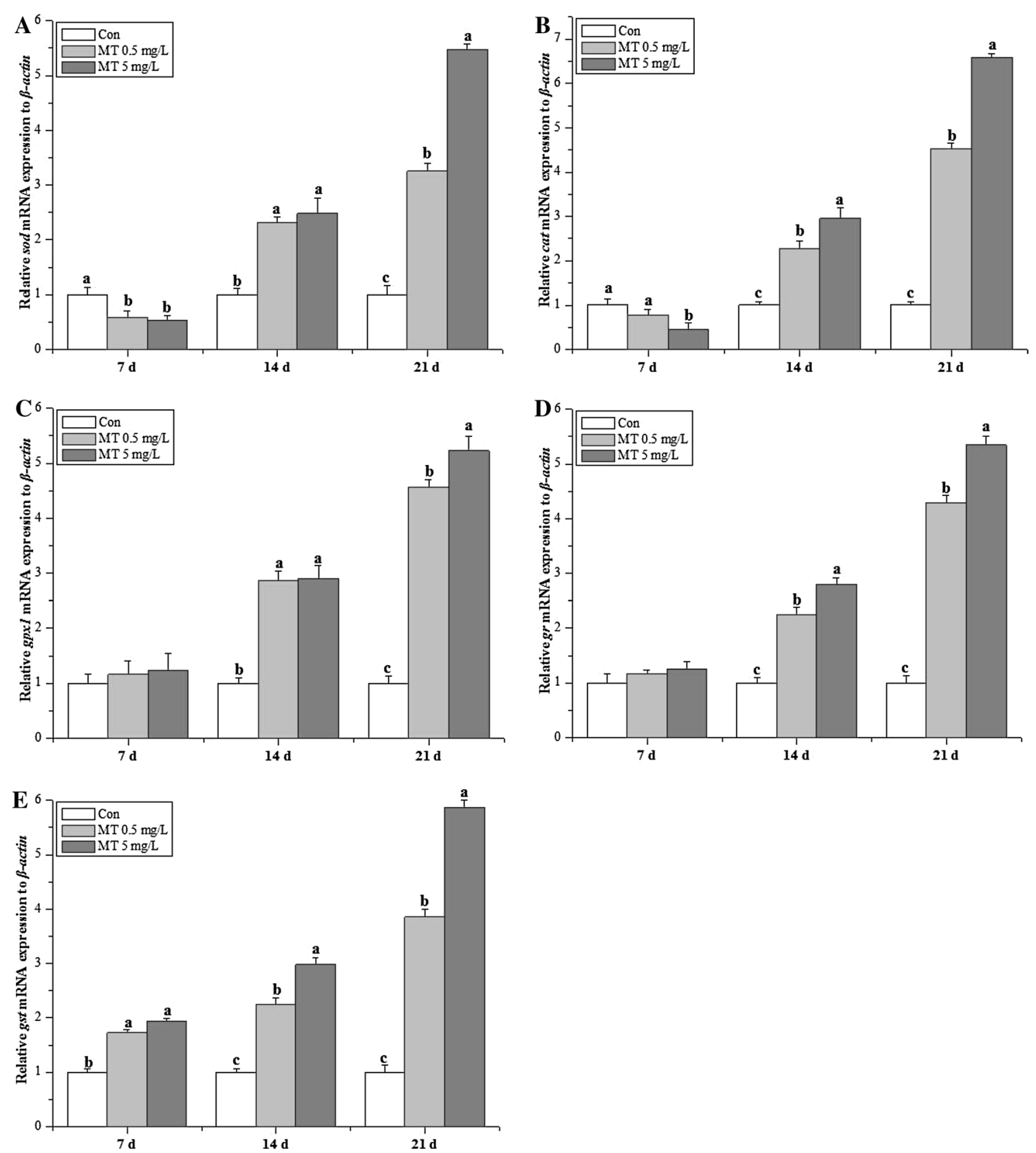

Fig. 3 Transcriptional gene expression profiles of O. niloticus juveniles under MT exposure. A sod, B cat, C gpx1, D gr, E gst

MT exposure groups was significant lower than those in $0.5 \mathrm{mg} / \mathrm{L}$ MT exposure groups at 14 days. The genotoxicity data showed that these detected parameters presented the dose-dependent manner at 14 days (except for sod, gpx1) and 21 days. To conclude, genotoxicity was more sensitive than enzymatic parameters based on the data observed in the current study (Chakravarthy et al. 2014).

SOD, CAT and GST activities showed almost the same tendency in the present study, which provided inconsistent data to the study demonstrated as different response under chlorpyrifos exposure (Jin et al. 2015). CAT and GPx can act cooperatively as scavengers of $\mathrm{H}_{2} \mathrm{O}_{2}$ and other hydroperoxides. Vieira et al. (2012) reported the decreased CAT activity was concomitant with the stimulated SOD and GPx activity in goldfish under acute toxicity of manganese exposure. The present study showed the reverse tendency between SOD, CAT activities with GPx activity for treated groups at 7 days, especially in 
treated groups at 14 days in the present study, which demonstrated that CAT activity could be compensated by a high decrease of the GPx activity (Atli and Canli 2011). GST activity was also significantly induced at $5 \mathrm{mg} / \mathrm{L} \mathrm{MT}$ groups, which in agreement with the study observed in Leuciscus cephalus exposed to heavy metals (Hermenean et al. 2015). The decreased total GSH observed in the present study was the same as methylmercury-exposed in rainbow trout (Mozhdeganloo et al. 2015), while different from waterborne lead exposure for tilapia (Kaya and Akbulut 2015). The alteration of GSH content and metabolism in different studies suggest that GSH has a key role in oxidative-induced toxicity caused by MT. The reduction in the levels of MDA in the present study is not in agreement with the study performed by Mozhdeganloo et al. (2015). The decrease in the GSH/GSSG ratio for $0.5 \mathrm{mg} / \mathrm{L} \mathrm{MT}$ exposure groups in the present study, implied the oxidation of GSH to GSSG with the signal of increased detoxification of ROS (Guzmán-Guillén et al. 2013), which was the same as tilapia liver under spinosad exposure (Piner and Üner 2013).

The transcriptional changes in these genes in the liver could be good biomarkers for stress levels in O. javanicus exposed to iprobenfos (Woo et al. 2009), and this study indicates that transcripts of the detected antioxidant enzymes were significant increased except for sod and cat. The down-regulation of sod and cat was the same as the study performed in juvenile Jian carp challenging against dietary choline (Wu et al. 2014). However, the up-regulate sod, cat and $g r$ mRNA levels, which suggesting an adaptive mechanism against stress in Jian carp (Jiang et al. 2014). The transcriptional and functional responses of antioxidant enzymes are inversely correlated in GIFT tilapia when exposed to MT, which was demonstrated in common carp exposed to organochlorine pesticides (Karaca et al. 2014). The dose-dependent pattern revealed in the present study was the same as the study of benzo[a]pyrene on marine medaka Oryzias melastigma (Kim et al. 2014), atrazine exposure on zebrafish (Jin et al. 2010), methomyl on Nile tilapia (Meng et al. 2014a, b). This study indicates that although MT stimulates adaptive increases in the expression of some antioxidant enzyme genes, it also induces oxidation and the depletion of most activities of antioxidant enzyme (Fig. 2a, b except for $5 \mathrm{mg} / \mathrm{L} \mathrm{MT}$ at 14 days, Fig. 2e except for $0.5 \mathrm{mg} / \mathrm{L}$ MT at 14, 21 days) and GSH content (Fig. 1a) due to the increase of ROS production (Meng et al. 2014a, b; Mukhopadhyay et al. 2015). To conclude, genotoxicity are reliable environmental biomarkers for MT induced oxidative stress in tilapia juveniles, while SOD, CAT, GPx, GST, T-AOC (5 mg/L MT) also be sensitive for MT exposure. Therefore, the useful biological indicators of environmental MT contamination revealed for the aquatic ecosystem (Kayode et al. 2014).

\section{Conclusion}

Antioxidative parameters (T-GSH, GSH/GSSG and MDA) and antioxidant enzymes (SOD, CAT and GST) significantly decreased under MT exposure, and the genotoxicity profile of antioxidant enzymatic genes revealed as the dose-dependent manner. The current study presented evidence that MT could result in oxidative stress response in the early stages of GIFT tilapia.

\section{Additional file}

Additional file 1: Table S1. The primers of tilapia used for qRT-PCR in the study.

\section{Authors' contributions}

Experimental design: YZ, JZC; data collection: JHQ, LPQ, LMF, SLM, CS, data analysis: GDH, XWB; writing the article: YZ, JZC. All authors read and approved the final manuscript.

\section{Author details}

${ }^{1}$ Freshwater Fisheries Research Center, Chinese Academy of Fishery Sciences, No. 9 Shanshui East Rd., Wuxi 214081, Jiangsu, China. ${ }^{2}$ Scientific Observing and Experimental Station of Fishery Resources and Environment in the Lower Reaches of the Changjiang River, Wuxi 214081, China. ${ }^{3}$ Wuxi Fisheries College, Nanjing Agricultural University, Wuxi 214081, China.

\section{Acknowledgements}

We thank Kamira Barry for providing grammar and spelling check of the manuscript. The work was supported by Special Fund for Agro-scientific Research in the Public Interest (2015JBFR03), China Agriculture Research System (CARS49) and National Science and Technology Pillar Program (2015BAD13B03).

\section{Competing interests}

The authors declare that they have no competing interests.

Received: 19 November 2015 Accepted: 29 February 2016

Published online: 15 March 2016

\section{References}

Ahmad I, Maria VL, Oliveira M, Pacheco M, Santos MA (2006) Oxidative stress and genotoxic effects in gill and kidney of Anguilla Anguilla L. exposed to chromium with or without pre-exposure to $\beta$-naphthoflavone. Mutat Res 608:16-28

Albertsson E, Larsson DG, Förlin L (2010) Induction of hepatic carbonyl reductase/20beta-hydroxysteroid dehydrogenase mRNA in rainbow trout downstream from sewage treatment works-possible roles of aryl hydrocarbon receptor agonists and oxidative stress. Aquat Toxicol 97(3):243-249

Atli G, Canli M (2011) Essential metal (Cu, Zn) exposures alter the activity of ATPases in gill, kidney and muscle of tilapia Oreochromis niloticus. Ecotoxicology 20(8):1861-1869

Beutler E, Kelly BM (1963) The effect of sodium nitrite on red cell GSH. Experientia 19:96-97

Bradford MM (1976) A rapid and sensitive method for the quantitation of microgram quantities of protein utilizing the principle of protein-dye binding. Anal Biochem 72:248-254

Chakravarthy S, Sadagopan S, Nair A, Sukumaran SK (2014) Zebrafish as an in vivo high-throughput model for genotoxicity. Zebrafish 11(2):154-166 
Chen D, Zhang Z, Yao H, Liang Y, Xing H, Xu S (2015) Effects of atrazine and chlorpyrifos on oxidative stress-induced autophagy in the immune organs of common carp (Cyprinus carpio L.). Fish Shellfish Immunol 44(1):12-20

Gabriel NN, Qiang J, Ma XY, He J, Xu P, Liu K (2015) Dietary Aloe vera improves plasma lipid profile, antioxidant, and hepatoprotective enzyme activities in GIFT-tilapia (Oreochromis niloticus) after Streptococcus iniae challenge. Fish Physiol Biochem 41(5):1321-1332

Golan M, Levavi-Sivan B (2014) Artificial masculinization in tilapia involves androgen receptor activation. Gen Comp Endocrinol 207:50-55

Góth L (1991) A simple method for determination of serum catalase activity and revision of reference range. Clin Chim Acta 196(2-3):143-151

Guzmán-Guillén R, Prieto Al, Vasconcelos VM, Cameán AM (2013) Cyanobacterium producing cylindrospermopsin cause oxidative stress at environmentally relevant concentrations in sub-chronically exposed tilapia (Oreochromis niloticus). Chemosphere 90(3):1184-1194

Hermenean A, Damache G, Albu P, Ardelean A, Ardelean G, Puiu Ardelean D, Horge M, Nagy T, Braun M, Zsuga M, Kéki S, Costache M, Dinischiotu A (2015) Histopatological alterations and oxidative stress in liver and kidney of Leuciscus cephalus following exposure to heavy metals in the Tur River, North Western Romania. Ecotoxicol Environ Saf 119:198-205

Homklin S, Wattanodorn T, Ong SK, Limpiyakorn T (2009) Biodegradation of 17alpha-methyltestosterone and isolation of MT-degrading bacterium from sediment of Nile tilapia masculinization pond. Water Sci Technol 59(2):261-265

Homklin S, Ong SK, Limpiyakorn T (2012) Degradation of 17a-methyltestosterone by Rhodococcus sp. and Nocardioides sp. isolated from a masculinizing pond of Nile tilapia fry. J Hazard Mater 221-222:35-44

Huang DJ, Zhang YM, Song G, Long J, Liu JH, Ji WH (2007) Contaminantsinduced oxidative damage on the carp Cyprinus carpio collected from the upper Yellow River, China. Environ Monit Assess 128(1-3):483-488

Ibrahim AT, Harabawy AS (2014) Sublethal toxicity of carbofuran on the African catfish Clarias gariepinus: hormonal, enzymatic and antioxidant responses. Ecotoxicol Environ Saf 106:33-39

Jiang WD, Liu Y, Hu K, Jiang J, Li SH, Feng L, Zhou XQ (2014) Copper exposure induces oxidative injury, disturbs the antioxidant system and changes the Nrf2/ARE (CuZn-SOD) signaling in the fish brain: protective effects of myo-inositol. Aquat Toxicol 155:301-313

Jin Y, Zhang X, Shu L, Chen L, Sun L, Qian H, Liu W, Fu Z (2010) Oxidative stress response and gene expression with atrazine exposure in adult female zebrafish (Danio rerio). Chemosphere 78(7):846-852

Jin Y, Zhang X, Lu D, Fu Z (2012) Proteomic analysis of hepatic tissue in adult female zebrafish (Danio rerio) exposed to atrazine. Arch Environ Contam Toxicol 62(1):127-134

Jin Y, Liu Z, Peng T, Fu Z (2015) The toxicity of chlorpyrifos on the early life stage of zebrafish: a survey on the endpoints at development, locomotor behavior, oxidative stress and immunotoxicity. Fish Shellfish Immunol 43(2):405-414

Karaca M, Varışlı L, Korkmaz K, Özaydın O, Perçin F, Orhan H (2014) Organochlorine pesticides and antioxidant enzymes are inversely correlated with liver enzyme gene expression in Cyprinus carpio. Toxicol Lett 230(2):198-207

Kaya H, Akbulut M (2015) Effects of waterborne lead exposure in mozambique tilapia: oxidative stress, osmoregulatory responses, and tissue accumulation. J Aquat Anim Health 27(2):77-87

Kayode SJ, Chidimma UI, Alwell EE (2014) Response of some antioxidant parameters in post juveniles of Clarias gariepinus after exposure to nigerian crude oil (Forcados, Bonny Light and Qua-lboe). Pak J Biol Sci 17(12):1225-1230

Kim BM, Rhee JS, Jeong CB, Lee SJ, Lee YS, Choi IY, Lee JS (2014) Effects of benzo[a]pyrene on whole cytochrome P450-involved molecular responses in the marine medaka Oryzias melastigma. Aquat Toxicol 152:232-243

Kroon FJ, Hook SE, Jones D, Metcalfe S, Osborn HL (2014) Effects of atrazine on endocrinology and physiology in juvenile barramundi, Lates calcarifer (Bloch). Environ Toxicol Chem 33(7):1607-1614

Larsson DG, Kinnberg K, Sturve J, Stephensen E, Skön M, Förlin L (2002) Studies of masculinization, detoxification, and oxidative stress responses in guppies (Poecilia reticulata) exposed to effluent from a pulp mill. Ecotoxicol Environ Saf 52(1):13-20

Livak KJ, Schmittgen TD (2001) Analysis of relative gene expression data using realtime quantitative $P C R$ and the $2^{-\triangle \Delta C T}$ method. Methods 25:402-408

Luo Y, Su Y, Lin RZ, Shi HH, Wang XR (2006) 2-chlorophenol induced ROS generation in fish Carassius auratus based on the EPR method. Chemosphere 65(6):1064-1073

Ma XY, Qiang J, He J, Gabriel NN, Xu P (2015) Changes in the physiological parameters, fatty acid metabolism, and SCD activity and expression in juvenile GIFT tilapia (Oreochromis niloticus) reared at three different temperatures. Fish Physiol Biochem 41(4):937-950

Meng SL, Chen JZ, Hu GD, Song C, Fan LM, Qiu LP, Xu P (2014a) Effects of chronic exposure of methomyl on the antioxidant system in liver of Nile tilapia (Oreochromis niloticus). Ecotoxicol Environ Saf 101:1-6

Meng SL, Chen JZ, Xu P, Qu JH, Fan LM, Song C, Qiu LP (2014b) Hepatic antioxidant enzymes SOD and CAT of Nile tilapia (Oreochromis niloticus) in response to pesticide methomyl and recovery pattern. Bull Environ Contam Toxicol 92(4):388-392

Mimeault C, Trudeau VL, Moon TW (2006) Waterborne gemfibrozil challenges the hepatic antioxidant defense system and down-regulates peroxisome proliferator-activated receptor beta (PPARbeta) mRNA levels in male goldfish (Carassius auratus). Toxicology 228(2-3):140-150

Mozhdeganloo Z, Jafari AM, Koohi MK, Heidarpour M (2015) Methylmercuryinduced oxidative stress in rainbow trout (Oncorhynchus mykiss) liver: ameliorating effect of vitamin C. Biol Trace Elem Res 165(1):103-109

Mukhopadhyay D, Srivastava R, Chattopadhyay A (2015) Sodium fluoride generates ROS and alters transcription of genes for xenobiotic metabolizing enzymes in adult zebrafish (Danio rerio) liver: expression pattern of Nrf2/ Keap1 (Nrf2). Toxicol Mech Methods 23:1-10

Piner P, Üner N (2013) Oxidative stress and apoptosis was induced by bioinsecticide spinosad in the liver of Oreochromis niloticus. Environ Toxicol Pharmacol 36(3):956-963

Rivero-Wendt CL, Miranda-Vilela AL, Ferreira MF, Borges AM, Grisolia CK (2013) Cytogenetic toxicity and gonadal effects of 17a-methyltestosterone in Astyanax bimaculatus (Characidae) and Oreochromis niloticus (Cichlidae). Genet Mol Res 12(3):3862-3870

Salaberria I, Hansen BH, Asensio V, Olsvik PA, Andersen RA, Jenssen BM (2009) Effects of atrazine on hepatic metabolism and endocrine homeostasis in rainbow trout (Oncorhynchus mykiss). Toxicol Appl Pharmacol 234(1):98-106

Schaedle M (1977) Chloroplast glutathione reductase. Plant Physiol 59(5):1011-1012

Seki M, Yokota H, Matsubara H, Maeda M, Tadokoro H, Kobayashi K (2004) Fish full life-cycle testing for androgen methyltestosterone on medaka (Oryzias latipes). Environ Toxicol Chem 23:774-781

Shen ZG, Fan QX, Yang W, Zhang YL, Wang HP (2015) Effects of 17a-methyltestosterone and aromatase inhibitor letrozole on sex reversal, gonadal structure, and growth in yellow catfish Pelteobagrus fulvidraco. Biol Bull 228(2):108-117

Sun L, Liu Y, Chu XG, Lin JM (2010) Trace analysis of fifteen androgens in environmental waters by LC-ESI-MS-MS combined with solid-phase disk extraction cleanup. Chromatographia 71(9-10):867-873

Vieira MC, Torronteras R, Córdoba F, Canalejo A (2012) Acute toxicity of manganese in goldfish Carassius auratus is associated with oxidative stress and organ specific antioxidant responses. Ecotoxicol Environ Saf 78:212-217

Woo S, Yum S, Kim DW, Park HS (2009) Transcripts level responses in a marine medaka (Oryzias javanicus) exposed to organophosphorus pesticide. Comp Biochem Physiol C 149(3):427-432

Wu P, Jiang WD, Liu Y, Chen GF, Jiang J, Li SH, Feng L, Zhou XQ (2014) Effect of choline on antioxidant defenses and gene expressions of Nrf2 signaling molecule in the spleen and head kidney of juvenile Jian carp (Cyprinus carpio var. Jian). Fish Shellfish Immunol 38(2):374-382

Zhang J, Ye Z, Lou Y (2004) Metabolism of chlorambucil by rat liver microsomal glutathione S-transferase. Chem Biol Interact 149(1):61-67

Zheng Y, Liang H, Xu P, Li M, Wang Z (2014) Molecular cloning of Pcc-dmrt1 s and their specific expression patterns in Pengze crucian carp (Carassius auratus var. Pengze) affected by 17a-methyltestosterone. Fish Physiol Biochem 40(4):1141-1155

Zorov DB, Juhaszova M, Sollott SJ (2006) Mitochondrial ROS-induced ROS release: an update and review. Biochim Biophys Acta 1757(5-6):509-517 